\title{
Fish Fauna of D'ering Memorial Wildlife Sanctuary and adjacent areas, Arunachal Pradesh, India
}

\author{
Debashree Dam and Anil Kumar* \\ Arunachal Pradesh Regional Centre, Zoological Survey of India, Itanagar - 791113, \\ Arunachal Pradesh, India; anilsonta@gmail.com
}

\begin{abstract}
D'Ering Memorial Wildlife Sanctuary is located in the eastern Arunachal Pradesh and known as bio-diversity rich area. Two field surveys were undertaken from 03.10 .2006 to 23.10 .2006 and 11.02 .09 to 18.02 .09 to study the fish diversity of this area. Analysis of the data revealed the occurrence of 18 species of fishes belonging to 5 orders and 7 families, including an interesting species namely Barilius arunachalensis. The area need to be surveyed extensively for a comprehensive record of fish fauna.
\end{abstract}

Keywords: Arunachal Pradesh, Barilius arunachalensis, D’Ering Memorial Wildlife Sanctuary, Fish fauna, Siang River

\section{Introduction}

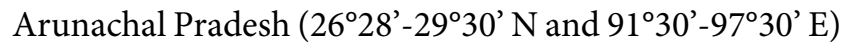
is recognized as global biodiversity hotspot and forms a complex hill system of Siwalik and Himalayan origin. It is crisscrossed by six major rivers and their tributaries. The state has 7000 ha and $2000 \mathrm{Km}$ of lentic and lotic water resources respectively. Of which, $30-40 \%$ is falling in the cold water zone of the state (Kaul and Haridasan, 1987; Kalita and Haridasan, 2001). Previous studies revealed that state is very rich in aquatic fauna (mainly Icthyofauna). During past years, few occasional surveys were conducted by some workers (Talwar and Jhingran, 1991; Jayaram, 1999; Nath and Dey, 2000). As per records of ZSI, fish fauna of Arunachal Pradesh comprised 143 species, under 61 genera, 21 families and 8 orders (Editor-Director, 2006). A recent study (Gurumayum et al., 2016) reports 259 fish species under 105 genera, 34 families and 11 orders. The family Cyprinidae forms the largest group with 95 species followed by Sissoridae (40 species), Bagridae (14 species), Channidae (8 species) and Cobitidae (11 species each) and the rest with one, two or three species. Review of literature revealed that there is still large gap in the knowledge on fish fauna of the state and most areas of state are still unexplored/ undocumented. Keeping the above background in view, present study was undertaken as a field survey programme of an ongoing departmental research project for the documentation of fish fauna of Arunachal Pradesh. Present investigation likely to be significant as it is the first detailed documentation of fish fauna of D'Ering Memorial Wildlife Sanctuary.

\section{Study Area and Methodology}

D'Ering Memorial Wildlife Sanctuary (hereafter DWS) located in the eastern Arunachal Pradesh and one of the bio-diversity rich areas of the state. It was notified as Lali Wildlife Sanctuary in 1978 vide notification no. FOR/284/78/2 dated 23-08-1978. Later on it was named as Daying Ering Memorial Wildlife Sanctuary vide notification no. CWL/37/83/D/T/4524-54 dated 27-10-1986. The total area of sanctuary is about 190 $\mathrm{km}^{2}$ including aquatic area of Siang river. The sanctuary located between $95^{\circ} 22^{\prime} \mathrm{E}-95^{\circ} 29^{\prime} \mathrm{E}$ and $27^{\circ} 51^{\prime} \mathrm{N}-28^{\circ} 05^{\prime}$ $\mathrm{N}$, and divided into three ranges namely Anchalghat, Namsing and Borguli (Figure 1). The sanctuary area mainly composed of two types of habitats. Most of the

\section{* Author for correspondence}


area (about 75\%) is alluvial grassland and rest is covered by semi evergreen forest patches. Most of the sanctuary area composed of islands formed between Siang River and its tributary Sibia River. Both the rivers divided into streams which intersect the sanctuary and form several islands (Figure 2 and 3). The topography of these islands changes from time to time depending upon the season, rainfall and flooded water (Kumar, 2009).

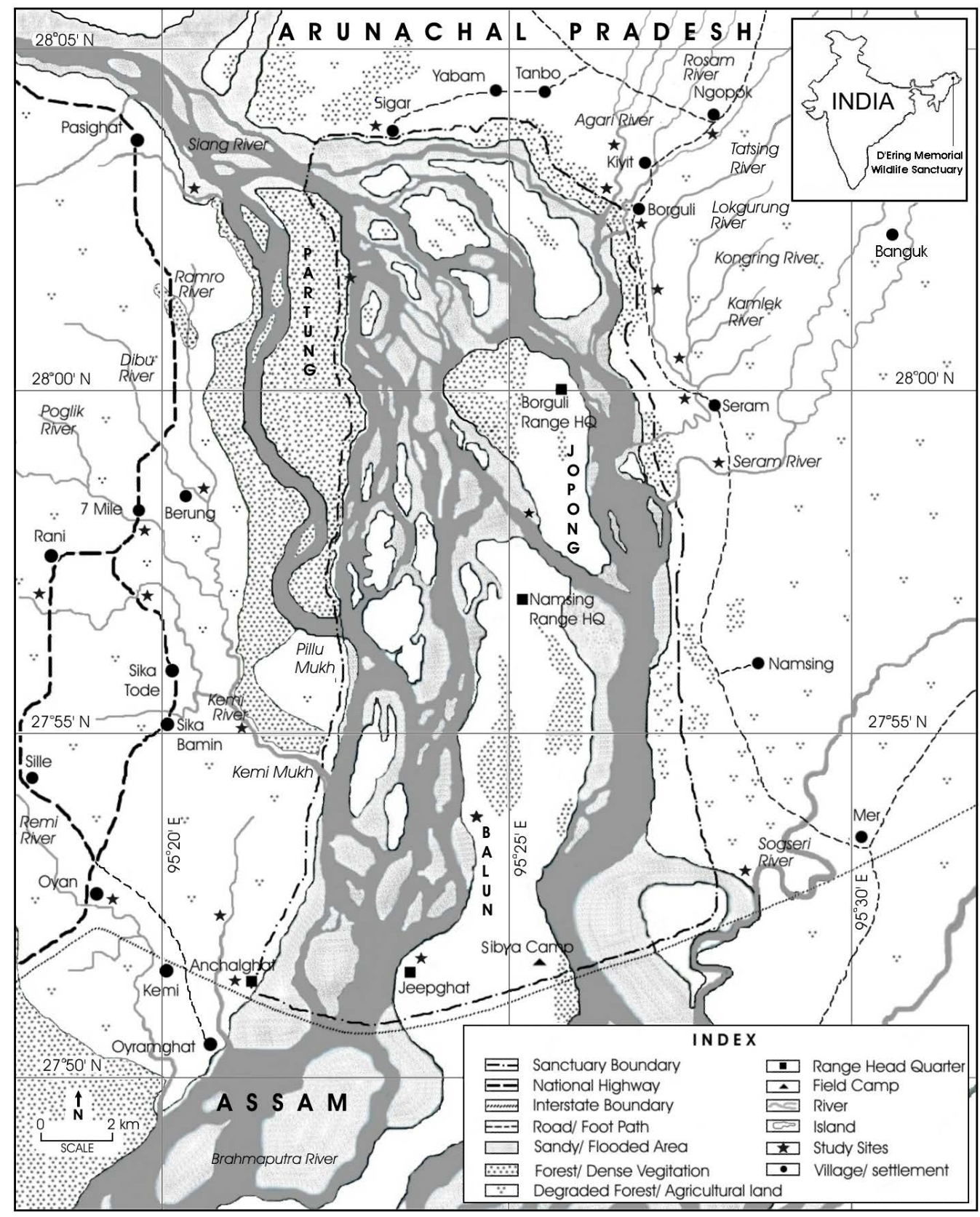

Figure 1. Map of the D'Ering Memorial Wildlife Sanctuary, showing the study sites. 


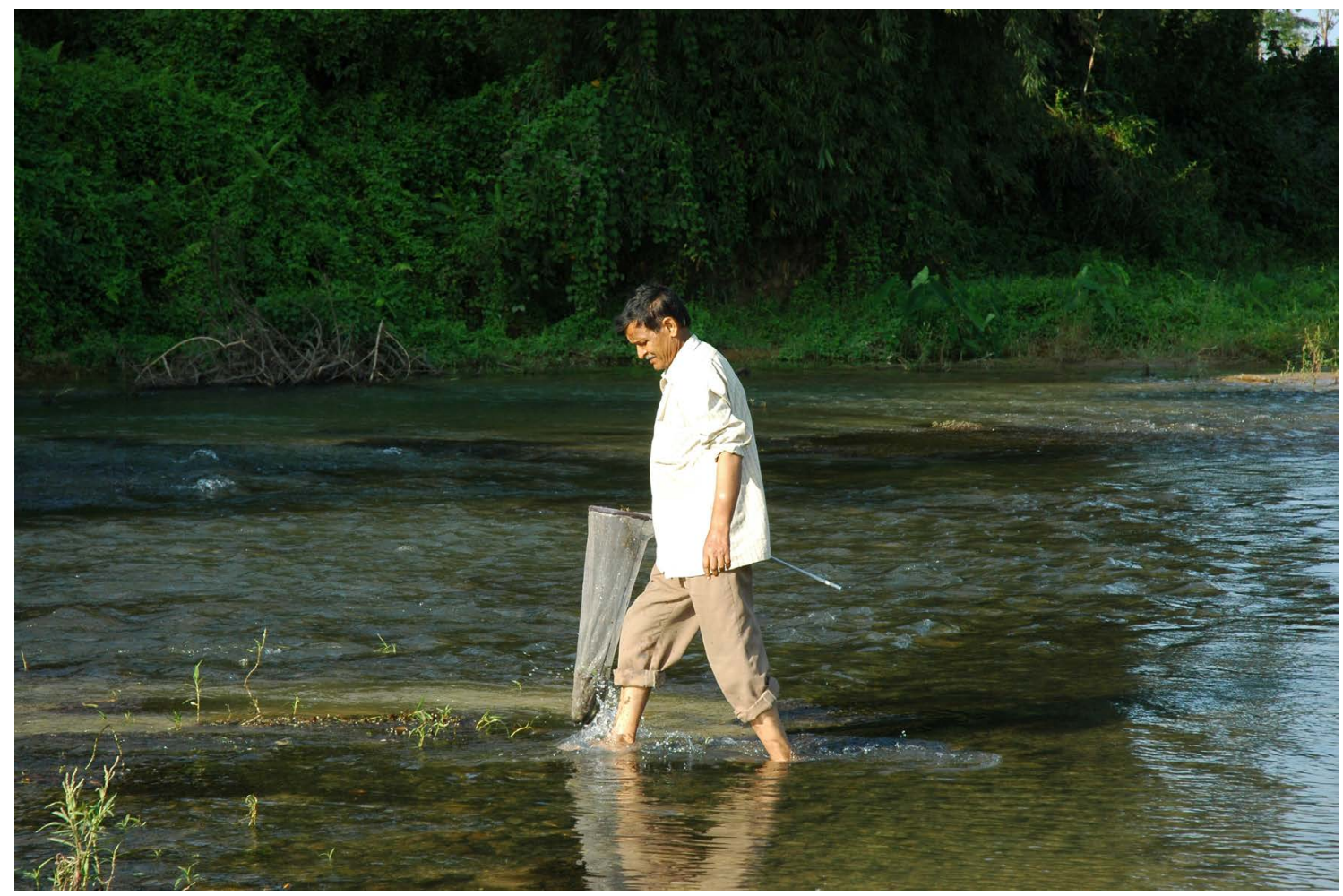

Figure 2. Photograph is showing the collection of fish samples near Agari River near Borguli village in north-east peripheral area of the sanctuary.

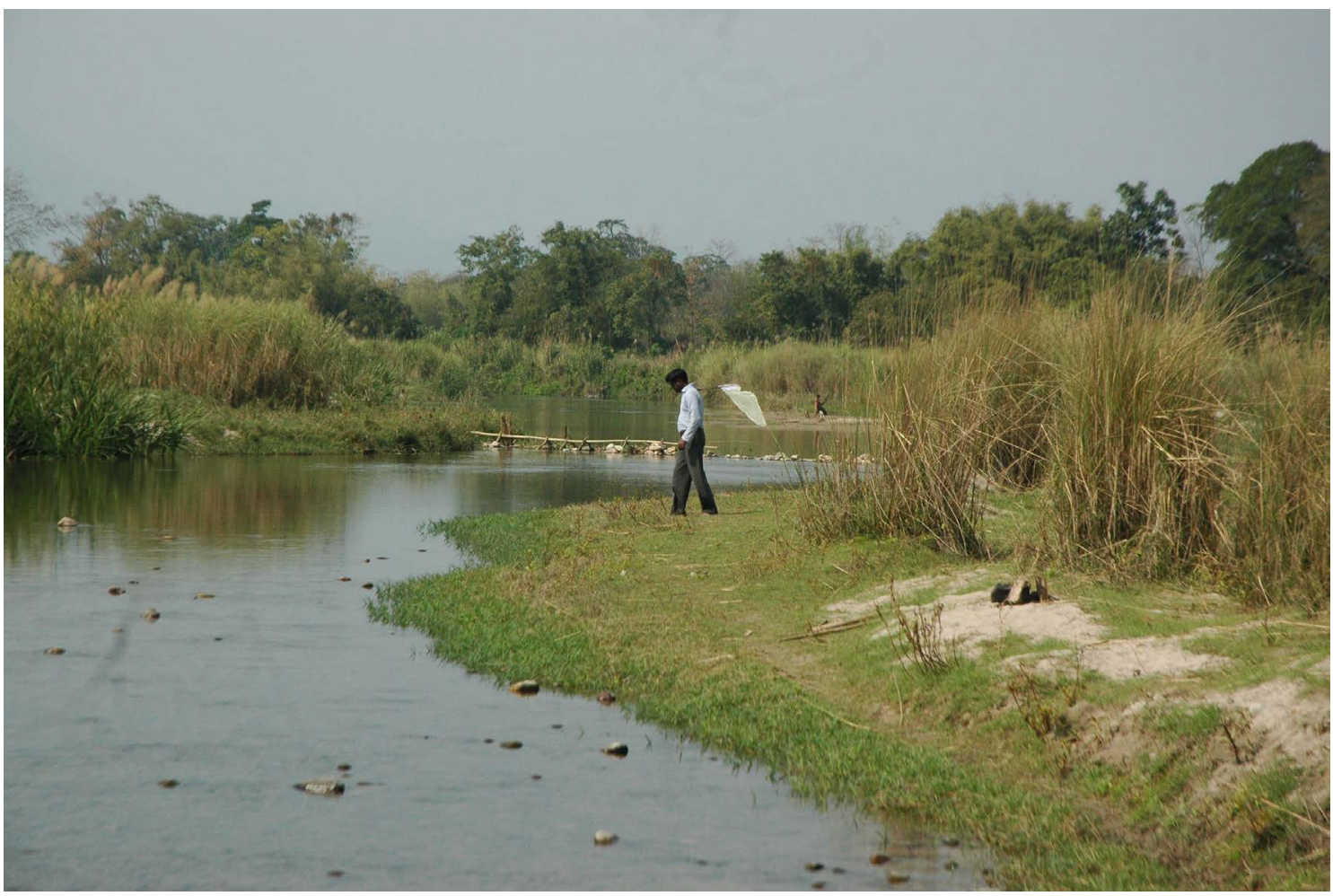

Figure 3. Photograph is showing the general topography and aquatic habitat near Sigar Village, located north to sanctuary. 
Field surveys were conducted from 03.10.2006 to 23.10.2006 and 11.02.09 to 18.02.09. During the survey different localities of DWS (namely Borguli Range, Jeepghat, Anchalghat and Namsing area) and surrounding areas (namely Mebo and surrounding area, Along road, Pasighat and surrounding area, Ruksin and surrounding area, Ranging village, Oyan village and Selluk village) were visited (please see the map of the study area). Mebo town located about $12 \mathrm{~km}$ from Borguli towards north and Selluk village located about $11 \mathrm{~km}$ from Mebo towards east (places are not shown in map). The specimens were collected using a cast net of $0.007 \mathrm{~m}$ mesh size and radius of $2.29 \mathrm{~m}$ and hand net. The representatives were photographed and after fixation they have been preserved in $10 \%$ formalin; registered and deposited in the APRC/ZSI, Itanagar.

\section{Results and Discussion}

Present study is based upon 44 specimens collected during surveys. The study revealed the record of 18 species under 7 families and 5 orders with the record of a new species (Nath, Dam \& Kumar, 2010). The systematic accounts of all of these species are given below. This systematic list has been developed based on the detailed taxonomic studies of the collected specimens. The classification by Nath and Dey (2000) has been followed with slight modification after Fish Base (Froese and Pauly, 2018). The nomenclature is followed after Fish Base (Froese and Pauly, 2009). Status of some of the species has been given as per BCPP, C.A.M.P. (1999).

\section{Systematic Account}

$\begin{array}{lll}\text { Phylum } & : & \text { CHORDATA } \\ \text { Class } & : & \text { PISCES } \\ \text { Sub-class } & : & \text { TELEOSTOMI } \\ \text { Order } & : & \text { CYPRINIFIORMES } \\ \text { Family } & : & \text { CYPRINIDAE }\end{array}$

1. Danio dangila (Hamilton, 1822)

1822. Cyprinus dangila Hamilton, Fish. Ganges, pp. 321, 390 (Type locality, Mountain streams of Mongher, Bihar).

Common Name: Dangila danio

Material examined: 15-20 exs were seen and examined at a stream near Portung forest, DWS, Arunachal Pradesh.
This is found in abundance hence the species were photographed and released in their natural habitat.

Distribution within North East: Throughout the north eastern states. Distribution in Arunachal Pradesh: Throughout the state in all major water bodies.

Special Remarks: This species was collected from a slow moving stream. The dorsal fin is inserted opposite between the ventral and anal fin. Two pairs of barbels present which are normally found to be longer than the diameter of the eye. Color was silvery with the presence of bluish lines.

\section{Devario aequipinnatus (McClelland, 1839)}

1839. Perilampus aequipinnatus McClelland, Asiat. Res., 19(2): 393, pl. 60, Figure 1 (Type locality, Assam).

\section{Common Name: Gaint Danio}

Material examined: 10 exs were seen and examined at a stream near Portung forest, 5 Exs. at Namsing; 04 Exs. at Anchal Ghat, DWS. As these species are abundantly found in this area the species were not collected but photographed, examined and released in their natural habitat.

Distribution within North East: Throughout the north eastern states. Distribution in Arunachal Pradesh: Throughout the state in all major water bodies.

Special Remarks: The dorsal fin is inserted just behind the ventral. Two pairs of barbels present and the caudal is forked. In a natural state the species shows the presence of three alternate bluish and yellowish bands.

\section{Devario devario (Hamilton, 1822)}

1822. Cyprinus devario Hamilton, Fish. Ganges, pp. 341, 393, pl. 6, fig. 94 (Type locality, West Bengal).

Common Name: Sind Danio

Material examined: 05 exs. (Regd. No.V/APFS/P-498), DWS; 08.10.06. 01 Ex. (Regd. No. V/APFS/P-508), Portung Forest, DWS, 12.02.09.

Distribution within North East: Assam, Arunachal Pradesh, Meghalaya, Nagaland and Tripura. Distribution 
in Arunachal Pradesh: East Siang District, Papumpare district, Changlang District, Lohit District.

Special Remarks: This species was collected from a slow moving stream. This species is also largely found to inhabit rivers, canals and ponds. Its status has been rated as Low Risk near threatened (LRnt). For its beautiful color pattern it can also be an important aquarium fish.

4. Cabdio morar (Hamilton, 1822)

1822. Cyprinus morar Hamilton, Fish Ganges, pp. 264, 384, pl. 31, Figure 75 (Type locality, rivers Yamuna and Tista).

\section{Common Name: Morari}

Material examined: 01 ex. (Regd. No.V/APFS/P-495), DWS; 08.10.06. $01 \mathrm{Ex}$.

Distribution within North East: Assam, Arunachal Pradesh, Manipur, Nagaland, Tripura. Distribution in Arunachal Pradesh: East Siang District, Papumpare district, Lohit District, Kameng, Tirap, Dibang valley.

Special Remarks: This species was collected from a stream from within the sanctuary and it is present in abundance. Its status has been rated as Low Risk near threatened (LRnt) but in Arunachal Pradesh it is reported from all major rivers in large numbers.

\section{Punctius chola (Hamilton, 1822)}

1822. Cyprinus chola, Hamilton, Fish. Ganges, pp. 312, 389, (Type locality, North Eastern parts of Bengal).

Common Name: Swamp barb

Material examined: 02 exs. (Regd. No.V/APFS/P-504), Sigar Village, DWLS; 17.02.09.

Distribution within North East: Assam, Arunachal Pradesh, Manipur, Meghalaya, Nagaland and Tripura. Distribution in Arunachal Pradesh: All major drainages of Arunachal Pradesh flowing through the foothills.

Special Remarks: The habitat of this species is shallow water in streams, canals and ponds. The specimens were collected from a puddle of water formed by the side of a slow moving stream. Its status has been evaluated as vulnerable at a national level but it is commonly found in all major drainages of Arunachal Pradesh flowing through the foothills. It can be easily identified by the presence of a deep black blotch present near base of caudal fin and the other at branched rays of dorsal fin.

\section{Pethia conchonius (Hamilton, 1822)}

1822. Cyprinus conchonius. Hamilton. Fish. Ganges. pp 317,389 (Type loc. North east Bengal and River Kosi).

Common Name: Rosy barb

Material examined: 4 exs. (Regd. No. V/APFS/P-505), Sigar village, DWS, 17.02.09

Distribution within NE: Assam, Arunachal Pradesh, Manipur, Mizoram, Nagaland, Tripura. Distribution within Arunachal Pradesh: River Kameng (West Kameng District), River Siang (East Siang District), Rivers Pachin and Dikrong (Papumpare District), Tirap District.

Special remarks: Its habitat comprises of fast flowing streams. It can be distinguished from $P$. chola by the absence of barbels (a pair of maxillary barbel present in P. chola) and a black blotch normally present at the 18$19^{\text {th }}$ scale on the lateral line. At the national level its status is vulnerable however in context to Arunachal Pradesh it is commonly found.

\section{Chagunius chagunio (Hamilton, 1822)}

1822. Cyprinus chagunio Hamilton. Fish. Ganges. pp.295, 385 (Type locality-Yamuna and northern rivers of Bihar and Bengal).

\section{Common Name: Chaguni}

Material examined: 01 Ex. (Regd. No. V/APFS/P-497), Sibia river near Borguli area, DWS, 8.10.06; 04 Exs. (Regd. No.V/APFS/P-503), Portung forest, DWS, 12.02.09; 05 Exs. (Regd. No.V/APFS/P-503) Anchal Ghat,DWS,13.03.09; 02 Exs. (Regd No. V/APFS/P- 503) Sigar village, 17.02.09; 03 Exs.9 (Regd No. V/APFS/P503), Naming area, 16.02.09. 
Distribution within NE: Assam, Arunachal Pradesh Manipur, Mizoram, Meghalaya, Nagaland, Tripura. Distribution within Arunachal Pradesh: All major drainages of Arunachal Pradesh

Special Remarks: It was collected from a fast flowing stream at Namsing, Anchal Ghat and Portung forest. However it was collected from a slow moving stream at Sigar village, also. This species can be easily identified by the presence of a strong dorsal spine serrated at its inner edge. Its status is vulnerable (Menon, 1999) but in Arunachal Pradesh it is abundantly found.

\section{Tor putitora (Hamilton, 1822)}

1822. Cyprinus putitora Hamilton. Fish Ganges. pp. 303, 388 (Type locality: Eastern parts of Bengal).

Common name: Putitor Mahseer

Material examined: 01 Ex. (Regd No. V/APFS/P- 496), Sibia river near Borguli area. DWS, 08.10.06.

Distribution within NE: Throughout North East. Distribution within Arunachal Pradesh: Almost all major drainages of Arunachal Pradesh.

Special remarks: The head length is much greater than its body depth. Silvery in color with pinkish tinge in the fins. This species was not seen in abundance. Its status is evaluated as endangered at the national level.

9. Tor tor (Hamilton, 1822)

1822. Cyprinus tor Hamilton. Fish Ganges. pp 305, 388 (Type locality: River Mahanadi, West Bengal).

Common name: Tor Mahseer

Material examined: 01 Ex. (Regd No. V/APFS/P- 496), Sibia River near Borguli area. DWS, 08.10.06. Distribution within NE: Assam, Arunachal Pradesh, Meghalaya, Nagaland.

Distribution within Arunachal Pradesh: Almost all major drainages of Arunachal Pradesh.
Special remarks: It was collected from Sibia River near Borguli area where the water level was almost 1 meter. It can be distinguished from Tor putitora by having a head length shorter than its body depth. At the national level its status is evaluated as endangered. This species can be used as in composite fish culture (Nath and Dey, 2000).

10. Barilius arunachalensis Nath et al. 2010

2010. Barilius arunachalensis Nath et al. 2010. Rec. zool. Surv. India, pp. 19-33.

(Type locality: Agari river mouth, D'Ering Wildlife Sanctuary, Arunachal Pradesh)

Common Name: Yet to be named

Material examined: 04 Exs. (Reg. No. APFS/ZSI/P-503), Agari river mouth, DWS, 07.10.08.

Distribution within NE: Arunachal Pradesh and possibly in Assam. Distribution within Arunachal Pradesh: Siang River and tributaries.

Special Remarks: It was found in the streams of Siang River. It has rough tubercles, prominent on snout \& lower jaw. Barbels were absent and snout was deeply humped. Lateral line scales were incomplete and ceases at the 35th scale. Dorsal fin extends to 3rd ray of Anal. Scales were large, cycloid and with oval spots at the dorsal side \& diamond shaped spots at the ventral surface and lateral line scales with single large spots and a few bilobed spots. Two broad bands were present with 'V' shaped on each side, behind gill opening.

Family: NEMACHEILIDAE

11. Acanthocobitis botia (Hamilton, 1822)

1822. Cobitis botia. Hamilton Fish, Ganges, pp350, 394 (Type Locality: Rivers of North Eastern parts of Bengal)

Common Name: Mottled Loach

Material examined: 02 Exs. (Regd No.V/APFS/P-507) Anchal Ghat, DWS, 13.02.09.

Distribution within NE: Arunachal Pradesh, Assam, Meghalaya, Nagaland, Tripura. Distribution within 
Arunachal Pradesh: All major drainages of Arunachal Pradesh

Special remarks: It is normally found in clear water, swift flowing streams with rocky pebbly and sandy bottom. However in the present study it was collected from a slow clear flowing secondary stream of Siang River. This species can be easily identified by the presence of a black ocellus at upper margin of the caudal fin and also presence of 3-4 '>' shaped dark bars in the caudal fin. It can be considered an important ornamental species owing to its beautiful coloration.

Family: COBITIDAE

\section{Lepidocephalichythys guntea (Hamilton, 1822)}

1822. Cobitis guntea. Ham. Fish. Ganges. pp. 353, 394 (Type locality - ponds and fresh waters of Bengal).

Common Name: Guntea Loach

Material examined: 04 Exs. (Regd. No. V/APFS/P 500 and 501) Sibia River near Borguli, DWS. 08.10.2006 and 13.10.06.

Distribution within NE: Throughout NE India.Distribution within Arunachal Pradesh: Almost all major drainages of Arunachal Pradesh.

Special remarks: This species is commonly found in all major drainages of Arunachal Pradesh. Its status has not been evaluated at the national level. This was collected from a flowing, clear secondary stream near Borguli area. This forms a good table fish in Arunachal Pradesh.

\section{Lepidocephalichythys annandalei Chaudhuri, 1912}

1912. Lepidocephalus annandalei Chaudhuri, Rec. Indian Mus., 7: $442 \mathrm{pl} 40$ figs 3, 3a, 3b ( Type locality-Rivers Tista and Mahananda).

Common name: Annandalei Loach

Material examined: 01 Ex. (Regd No. V/APFS/ZSI-P-506), Anchal Ghat, DWS.13.02.09

Distribution within NE: Arunachal Pradesh, Meghalaya, Manipur. Distribution within Arunachal Pradesh: All major drainages in Arunachal Pradesh.
Special remarks: It was collected from a clear slow moving secondary stream of the Siang River although its natural habitat has been recorded to be clear swift stream with sandy bottom (Talwar \& Jhingran). In the national level its status has been evaluated as LRnt and it is widely distributed in Arunachal Pradesh. It is similar to L. guntea and can be distinguished by the presence of two blackish spots or blotches in the caudal fin.

Order: SYNGNATHIFORMES

Family: OLYRIDAE

\section{Olyra longicaudata (McClelland, 1842)}

1842. Olyra longicaudata McClelland, Calcutta. J. Nat. Hist., 2: 588, fig.1 (Type locality: Khasi Hills, Meghalaya).

Common name: Himalayan Olyra

Material examined: 01 Ex. (Regd. No. V/APFS/P 509), Portung forest, DWS, 13.02.09.

Distribution within NE: Assam, Arunachal Pradesh, Nagaland, Tripura. Distribution within Arunachal Pradesh: All major drainages of Arunachal Pradesh.

Special remarks: Its status is not evaluated at the national level but it is found in abundance in Arunachal Pradesh. It was collected from a small flowing rocky stream inside a dense forest near Berung village. It can be identified by the presence of four pairs of barbels and the maxillary pair reaches up to ventral fin base and the nasal pair reaches beyond orbit; forked caudal fin, upper lobe longer than lower.

Order: BELONIFORMES

Family: BELONIDAE

\section{Xenetodon cancila (Hamilton, 1822)}

1822. Esox cancila Hamilton., Fish Ganges. pp. 213, 380. pl. 27. fig. 70 (Type locality-Gangetic Provinces).

Common name: Fresh water Garfish

Material examined: 01 Ex. (Regd. No. V/APFS/P -510), Sigar village, DWS, 13.02.09 
Distribution within NE: Throughout NE. Distribution within Arunachal Pradesh: All major drainages of Arunachal Pradesh.

Special remarks: The fish can be easily identified by the presence of its long beak like upper and lower jaw. The status of this species is LRnT, but it is found in abundance in Arunachal Pradesh in lower gradients. It has been collected from a natural pool formed on the side of a slow moving stream. This fish is edible and has good market as a table fish.

Order: SYNBRANCHIFORMES

Family: MASTACEMBELIDAE

\section{Mastacembelus armatus (Lacepede, 1800)}

1800. Macrognathus armatus Lacepede. Hist. Nat. poiss., 2: 286 (Type locality- not given).

Common name: Zig zag Eel

Materials examined: 01 Ex. (Regd. No. V/APFS/P- 511), Anchal Ghat, DWS, 13.02.09

Distribution within NE: Throughout the North East. Distribution within Arunachal Pradesh: Almost all major drainages of Arunachal Pradesh.

Special remarks: It was collected from a slow secondary stream of Siang river.

Order: PERCIFORMES

Family: CHANNIDAE

\section{Channa punctata (Bloch, 1793)}

1793. Ophiocephalus punctatus Bloch, Naturges Ausland. Fishe, 7: 139 pl. 358 (Type locality- Coromondol coast).

Common name: Spotted Snakehead

Material examined: 01 Ex. (Regd. No. V/APFS/P-494), Sibia River near Borguli Range, DWS, 08.10.06

Distribution within NE: Throughout the North East. Distribution within Arunachal Pradesh: River Subansiri (Lower Subansiri district), River Dikrong (Papumpare District).
Special remarks: It was collected from a stagnant pool of murky water on the side of Sibia River. It status is assessed as LRnt. It forms one of the species of cage culture and also responds to hypophysation (Nath \& Dey, 2000).

18. Channa marulius (Hamilton, 1822)

1822. Ophiocephalus marulius Hamilton. Fish Ganges. pp. 65. 367. pl. 17. fig 19 (Type locality-River Ganges).

Common name: Great Snake Head

Material examined: 01 Ex. (Regd. No.V/APFS/P-499), Sibia River near Borguli Range, DWS, 13.10.06

Distribution within NE: Assam, Arunachal Pradesh, Meghalaya, Manipur. Distribution within Arunachal Pradesh: River Subansiri (Lower Subansiri district), River Dikrong (Papumpare District), River Siang (East Siang district), Naodhing (Lohit district).

Special remarks: Its status is LRnT. Mostly found in sluggish or standing water and in the present study it was collected from a stagnant pool formed by the side of the Sibia River. This species is a recommended species for cage culture (Nath and Dey, 2000). This species can be easily distinguished from other close species of Channa by the presence of an ocellus at the upper portion of caudal fin.

\section{Conclusion}

The study revealed 18 species belonging to 5 orders and 7 families with the record of a new species of fish, Barilius arunachalensis (Nath, Dam \& Kumar, 2010) from DWS. Record of the new species throws light on the fact that DWS could be home to many more significant species of fish. The area need to be surveyed extensively for a comprehensive record of fish fauna of DWS. Seasonal studies and surveys in the monsoon months is suggested which is likely to reveal more rare/migrant species.

\section{Acknowledgements}

The authors are thankful to the Director, ZSI, Kolkata, to grant the permission for field surveys and Officerin-Charge, APRC, ZSI, Itanagar, for encouragement and departmental facilities. Kind support and active cooperation at various levels from Forest Department 
of Arunachal Pradesh is also gratefully acknowledged. Special thanks are due to DFO and staff of D'Ering WL Sanctuary and our colleague Dr. D. Suresh Chand, ZSI, and field staff (Mr. Dhan Bhadur Tamang and Mr. D.
Bhowmick and Sh. P. B. Thapa) for support and active cooperation in field. The authors are also thankful to Dr. P. Nath, Dept of Fisheries, and Government of Arunachal Pradesh for helping in identifying the fish samples.

\section{References}

BCPP, C.A.M.P. 1999. Freshwater fishes of India. Report Summary, 1998, Zoos' Print, 14(3): 1-28.

Editor-Director. 2006. Fauna of Arunachal Pradesh, State Fauna Series, 13 (Part-I): pp. 396.

Froese, R. and D. Pauly, Editors. 2018. FishBase. World Wide Web electronic publication. Available from: www.fishbase.org, version (06/2018).

Gurumayum, S. D., Kosygin, L., and Tamang, L. 2016. Ichthyofaunal diversity of Arunachal Pradesh, India: A part of Himalaya biodiversity hotspot. International Journal of Fisheries and Aquatic Studies, 4(2): 337-346.

Jayaram, K.C. 1999. The Freshwater Fishes of the Indian Region. Narendra Publishing House, Delhi, India, 551 pp

Kalita, S.N. and Haridasan K. 2001. Forest and wildlife management in Arunachal Pradesh. Arunachal Forest News, 19(1\&2): 26-31.

Kaul, R.N. and Haridasan K. 1987. Forest types of Arunachal Pradesh- A preliminary study. J. Econ. Tax. Bot., 9(2): $397-389$.

Kumar, A. 2009. Occurrence of mammals in D'Ering Memorial Wildlife Sanctuary and adjacent areas, Arunachal Pradesh, India. J. Env. Bio-sci. 23(1): 107-111.

Menon, A.G.K. 1999. Checklist Freshwater Fishes of India. Rec. zool. Surv. India, Occasional Paper, 175: 1-366

Nath, P. and Dey, S.C. 2000. Fish and Fisheries of North Eastern India (Arunchal Pradesh). Narendra Publishing House, Delhi, 200 pp.

Nath, P., Dam, D., \& Kumar, A. 2010. A new fish species of genus, Barilius (Cyprinidae: Rasborinae) from river Siang, D’Ering Memorial Wildlife Sanctuary, Arunachal Pradesh. Rec. zool. Surv. India, 110(3): 19-33.

Talwar, P.K and Jhingran, A. 1991. Inland Fishes of India and adjacent countries. Oxford and IBH publishing Co. Pvt. Ltd., New Delhi, $1158 \mathrm{pp}$ 


\section{PLATES}

Fishes photographed during the survey of D’Ering Memorial Wildlife Sanctuary and adjacent area

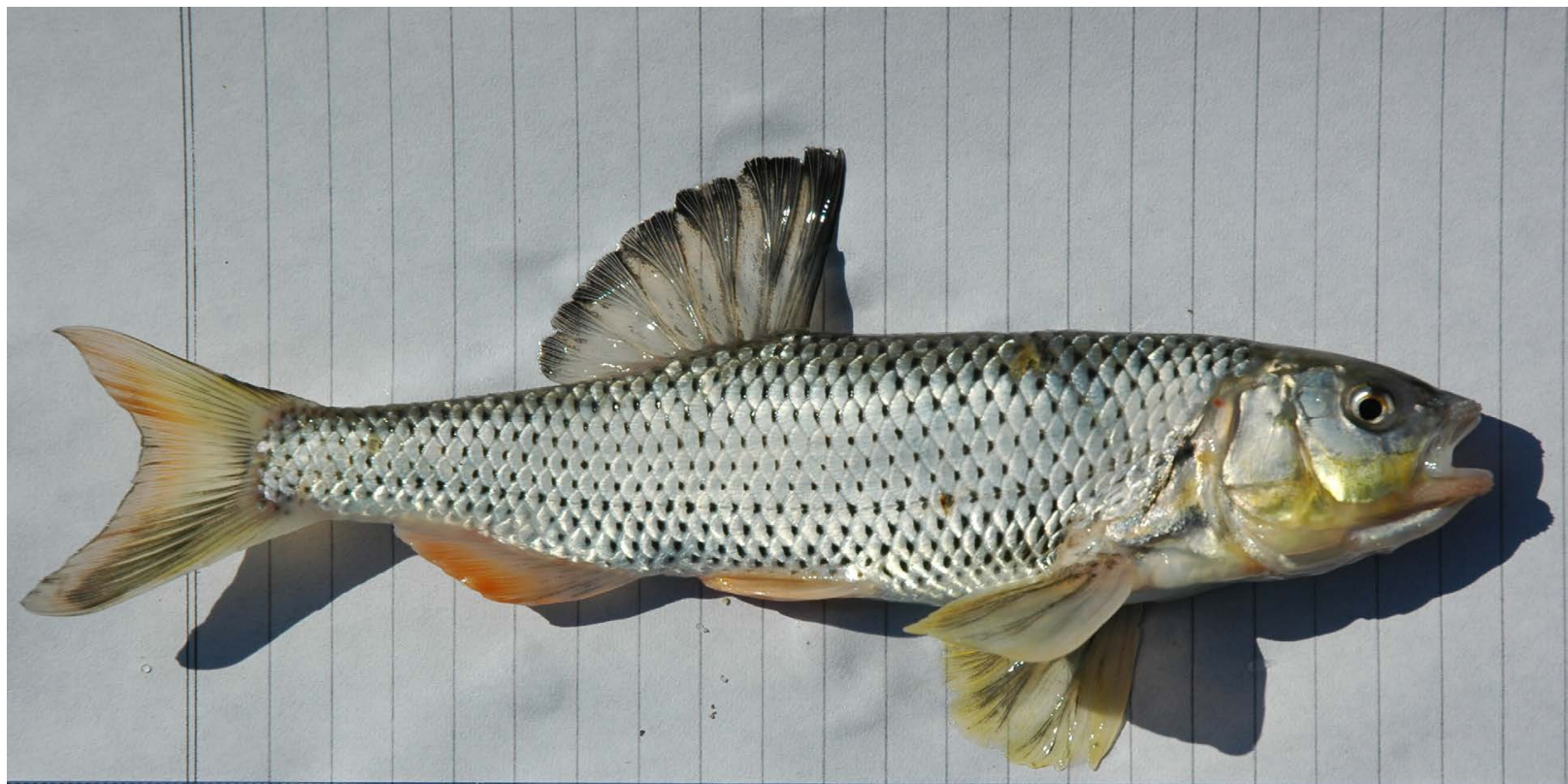

17'

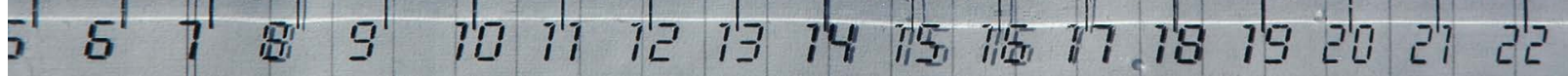

\section{Barilius arunachalensis}

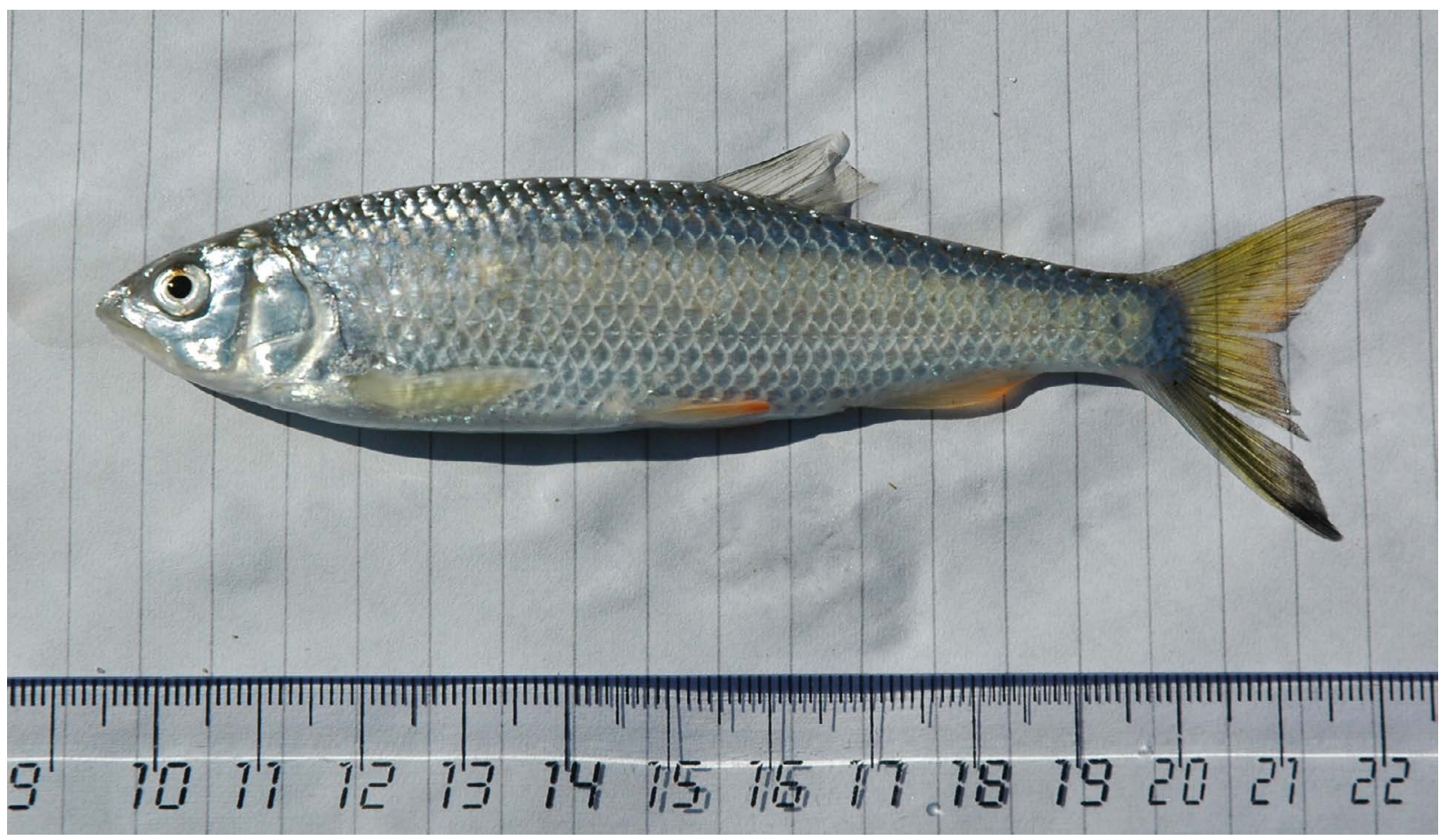

\section{Cabdio morar}




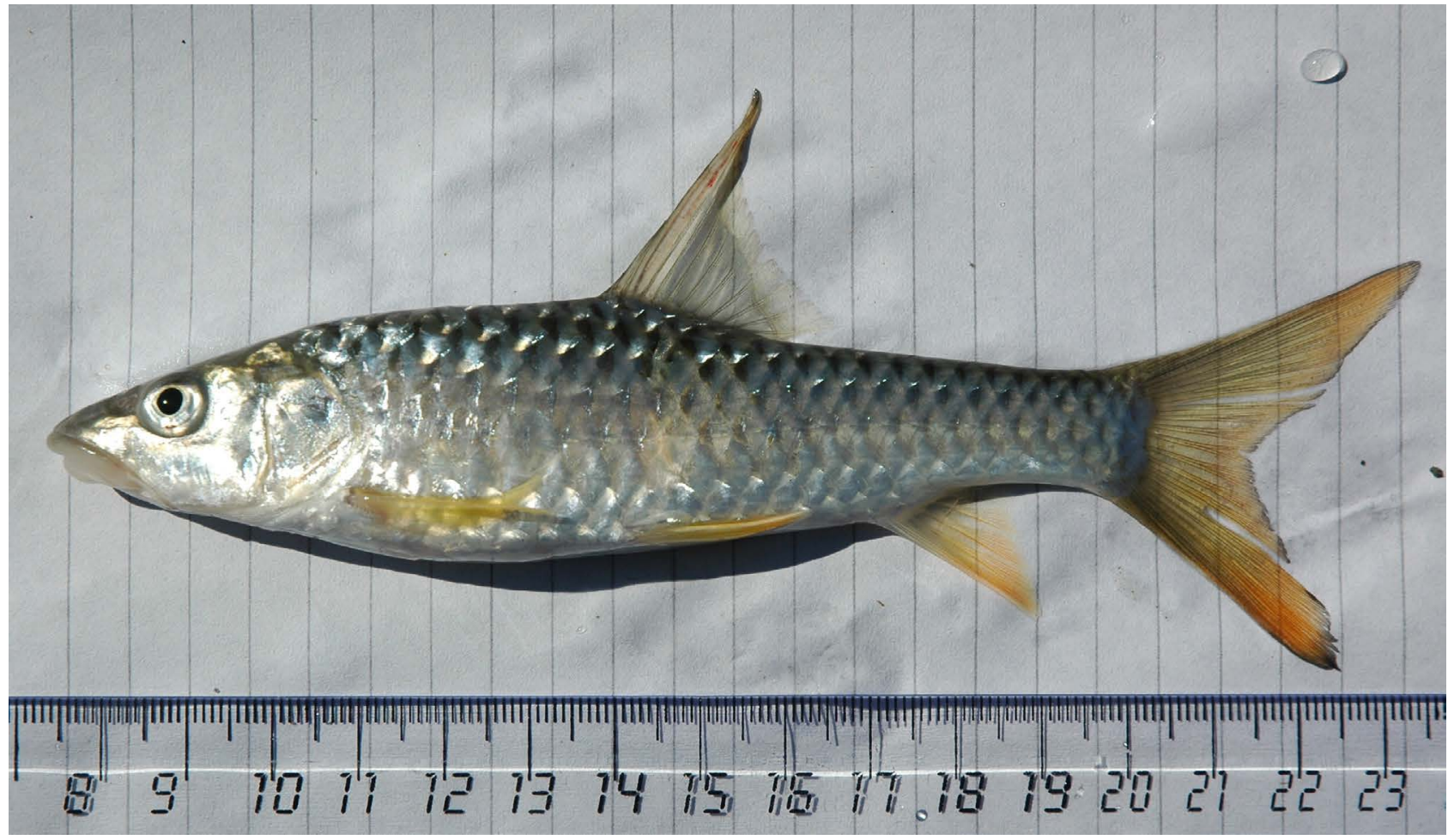

\section{Tor putitora}

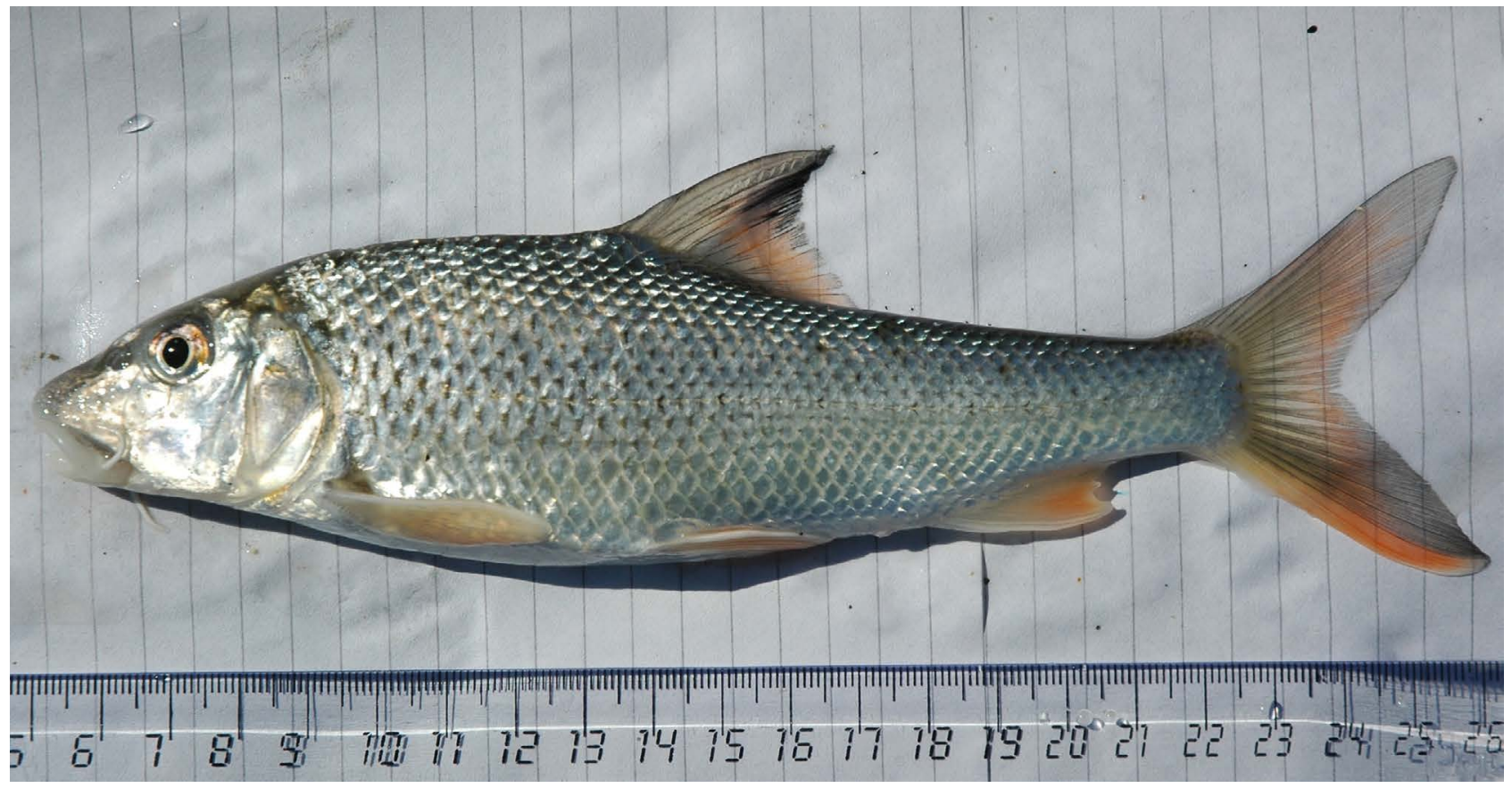

\section{Chagunius chagunio}




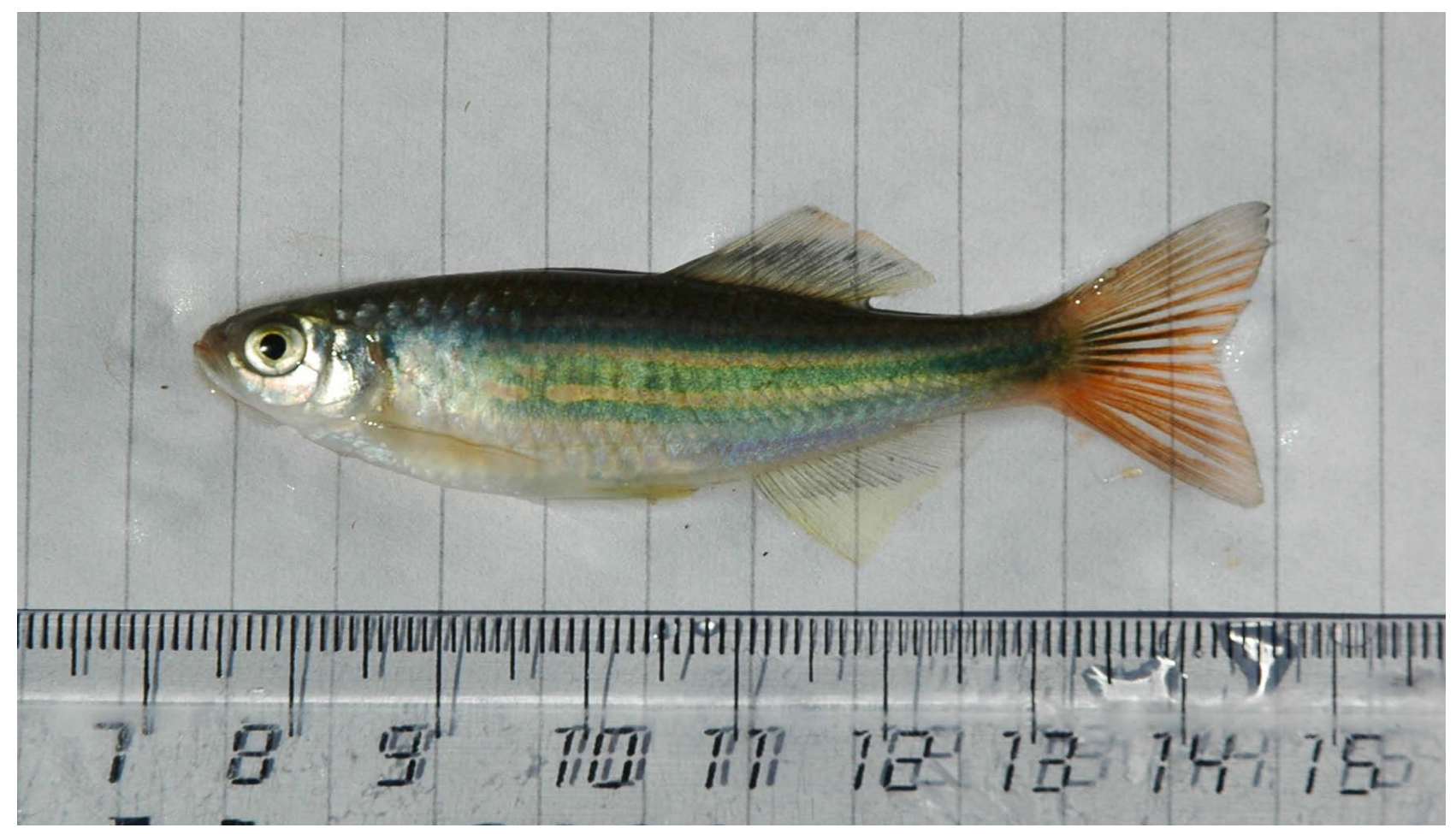

\section{Devario aequipinnatus}

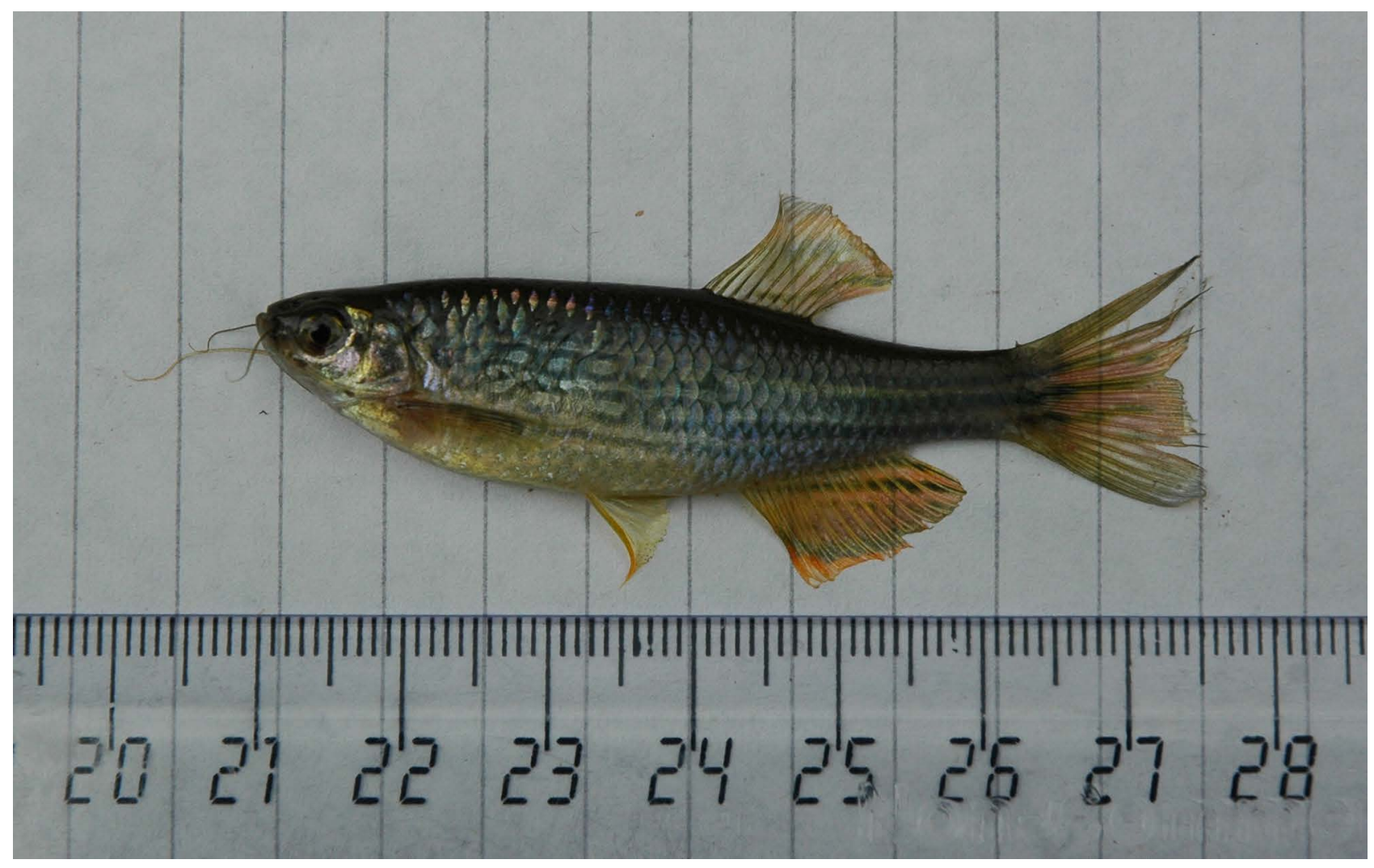

6. Danio dangila 